\title{
Understanding Patients' Experiences of Hayfever and its Treatment: A Survey of Illness and Medication Cognitions
}

\section{Helen Smith ${ }^{1 *}$, Carrie Llewellyn ${ }^{1}$, Alison Woodcock ${ }^{2}$, Peter White ${ }^{3}$ and Anthony Frew}

${ }^{1}$ Division of Primary Care and Public Health, Brighton \& Sussex Medical School, Brighton, UK

${ }^{2}$ Department of Psychology, Royal Holloway, University of London, Egham, Surrey, UK

${ }^{3}$ Nightingale Surgery, Romsey, UK

${ }^{4}$ Department of Respiratory Medicine, Royal Sussex County Hospital, Brighton, UK

\begin{abstract}
Background: Although effective medication for hayfever (seasonal allergic rhinitis) is available, treatment outcomes are often be poor. Patient beliefs influence outcomes in many other diseases. Assessing patients' beliefs about their illness and medication may identify targets for intervention to optimize self management and lessen disease impact.
\end{abstract}

Objective: The application of validated health-related analytical models (Leventhal's illness representations and Horne's beliefs about medications) to explore patients' understanding and experience of hayfever and its treatment.

Methods: Cross-sectional postal questionnaire sent to $20 \%$ sample of adults attending four General Practices in South England and prescribed medication for hayfever symptoms in the previous two years. Measures included the Revised IIIness Perception Questionnaire and the Beliefs about Medicines Questionnaire.

Results: $316 / 586$ questionnaires were returned (54\%). Cluster analysis identified two patient groups; those with negative beliefs $(n=132)$ and those with more positive beliefs about hayfever and its treatment $(n=182)$. Those with negative beliefs were more likely to believe that their hayfever would last for a long time, that they have little personal control over their illness and that their treatment is not effective. Conversely, they reported greater consequences, greater emotional impact, less understanding of hayfever and more medication concerns than those with more positive beliefs.

Conclusions and clinical relevance: Patients with hayfever fall into two distinct groups: nearly half $(41 \%$ of those sampled) have negative beliefs about their condition. Eliciting patient beliefs during the consultation may reveal assumptions that differ from those of healthcare professionals. Such beliefs should be considered when negotiating treatment plans.

Keywords: Beliefs about medication; General practice; Hayfever; Illness representations

Abbreviations: SAR: Seasonal Allergic Rhinitis; GPs: General Practitioners; ICD9: International Classification of Disease version 9; SRM: Leventhal's Self Regulatory Model of illness or Self Regulatory Model; IPQ-R: Revised Illness Perception Questionnaire; BMQ-specific: Beliefs about Medicines Questionnaire -specific version; BMQ-hayfever: Beliefs about Medicines Questionnaire -hayfever version; SPSS: Statistical Package for the Social Sciences

\section{Introduction}

Seasonal allergic rhinitis (SAR), commonly known as hayfever, is a common and growing challenge in Primary Care. Increasing numbers of patients present with symptoms [1] and suboptimal use of medication is widespread [2]. The reported incidence of SAR is between $2-15 \%$, depending on the diagnostic criteria and population [3]. The prevalence of SAR in UK school children has increased since the 1960s $[1,4,5]$ and the lifetime prevalence of SAR also continues to increase in adults [6]. This rising prevalence has been reflected in increased use of health services. Consultations with general practitioners (GPs) have increased [1]: the number of patients of all ages consulting GPs for SAR in England and Wales (ICD9-477) doubled between 1971-1991 [6]. Between 1991 and 2004, Primary Care prescriptions for nasal allergy increased by over $60 \%$ (from 2.7 to 4.5 million/year) and ocular antiinflammatory prescriptions increased by $50 \%$ to 1.4 million/year [6]. While increases in prevalence statistics may reflect increased patient awareness or altered diagnostic practice, the increase in prescriptions does confirm that more people are seeking treatment for SAR [7].
Common symptoms of SAR include sneezing, runny or blocked nose and itchy eyes $[2,8]$. Despite the availability of a wide range of symptom-relieving medications, SAR can significantly affect sufferers' perceived health and quality of life [9-14]. Only a minority of SAR patients report good symptom control, although this statistic may be skewed because many people with SAR (44\%) do not consult a clinician [15]. Suboptimal use of medication and poor symptom control may result from not taking medications as instructed [2], which in other illnesses has been shown to be influenced by patients' beliefs [16,17].

Leventhal's Common Sense Model of self regulation of health and illness (SRM), provides a three-stage framework for understanding how symptom-based and psychological factors combine to form patients' own model of illness and how this influences coping strategies and outcomes $[18,19]$. Firstly, the person constructs cognitive and emotional representations of the health threat. These reflect internal cues

${ }^{*}$ Corresponding author: Helen Smith, Division of Primary Care and Public Health Brighton \& Sussex Medical School, Mayfield House, Falmer, Brighton, BN1 9PH, UK, Tel: 01273 644192; Fax: 01273 644440; E-mail: h.e.smith@bsms.ac.uk

Received May 14, 2012; Accepted June 23, 2012; Published June 28, 2012

Citation: Smith H, Llewellyn C, WoodcockA, White P, Frew A (2012) Understanding Patients' Experiences of Hayfever and its Treatment: A Survey of Illness and Medication Cognitions. J Aller Ther S5:008. doi:10.4172/2155-6121.S5-008

Copyright: (C) 2012 Smith $\mathrm{H}$, et al. This is an open-access article distributed under the terms of the Creative Commons Attribution License, which permits unrestricted use, distribution, and reproduction in any medium, provided the original author and source are credited. 
(symptoms), and/or external cues (information from friends, family and healthcare professionals). Five cognitive representations are described: identity: the signs and symptoms and the arbitrary label given to the condition; cause: the individual's perceived cause of the condition, which may differ from healthcare professionals' views; time-line: beliefs about the likely duration of the condition; consequences: beliefs about the consequences of the condition for the individual and his/her life; curability/controllability: beliefs about whether the condition can be cured or controlled, including how much the individual can control this. Alongside these cognitive representations, the SRM includes emotional representations which reflect the emotional responses to the condition.

At stage two, the individual adopts an action plan or coping procedure linked to their beliefs and emotions. Personal strategies may aim to achieve and maintain symptomatic control by seeking advice and medication (problem-focused coping) or may involve avoiding going outdoors, taking time off work, or reducing anxiety by meditating (emotion-focused coping). The third stage is coping appraisal, which involves evaluating the effectiveness of the coping strategy in dealing with the threat (in this case the symptoms of SAR). This evaluation feeds back to influence illness representations and coping strategies. The underlying aim is to restore the status quo, cognitively, physically and emotionally. If the patient is prescribed medication, their beliefs about medication will probably impact on coping mechanisms and outcomes [20] so it is useful to measure these in addition to illness beliefs $[16,21]$.

The SRM has been used to study patient beliefs in many illnesses [22-24] including asthma $[16,25,26]$, leading to better understanding of how patients perceive and cope with chronic conditions and how beliefs affect health outcomes such as depression and quality of life. In patients with myocardial infarction (MI) interventions to change inappropriate cognitions regarding their illness have facilitated faster recovery rates [27] and provided patients with a greater sense of control over their illness [28]. Research on self-managed illnesses such as asthma has addressed the impact of illness and medication beliefs on adherence to medication $[16,25,26]$ but these findings still await translation into effective patient interventions.

The illness representations of patients with SAR have not been studied, although one recent study looked at allergies in general [29]. The present study aimed to explore the beliefs that SAR patients hold regarding their illness and treatments, and to determine whether patients could be usefully classified according to the configuration of their illness beliefs.

\section{Methods}

\section{Design}

Cross-sectional postal questionnaire survey.

\section{Participants}

Adult patients (aged 17-65 years) who had consulted with SAR at least once in the preceding two years were identified from computerised records of four General Practices in Southern England.

\section{Procedure}

Questionnaires were distributed to a $20 \%$ random sample of patients with SAR in August, at the end of the grass pollen season. Selfcompletion packs were distributed with a covering letter from the GP, and a freepost reply envelope.

\section{Demographic and descriptive data}

Age, gender, current symptoms and age of symptom onset were collected by questionnaire.

\section{Measures}

The following self-completed measures were used to elicit illness representations and medication beliefs:

Revised Illness Perception Questionnaire (IPQ-R): The revised Illness Perception Questionnaire (IPQ-R) [30] was chosen to assess patient's beliefs and understanding of their illness, as it has proven validity and reliability across a range of illness groups. It provides a quantitative measure of the nature and strength of patient cognitions and emotional representations on nine subscales.

The illness identity scale assesses the number and nature of symptoms that patients endorse as part of their condition. Participants are asked to state whether they have experienced any of 14 general symptoms (e.g. fatigue, sore eyes, headaches, sleep difficulties) since their illness began. They are then asked whether they believe the symptom to be specifically due to hayfever (yes/no) which are then summed to give the illness identity subscale score. The causal scale assesses personal perceptions of the likely cause of the illness and contains a core set of 18 belief items (e.g. pollution, diet, overwork). For this study 'pollen' was added as an additional causal item.

Illness cognitions are assessed through five subscales: perceived consequences of the illness (6 items, score 6-30) concerned with the expected effects and outcomes of the illness e.g. 'my hayfever causes difficulties for those that are close to me'; how much personal control the patient feels they have over their illness (6 items, score 6-30) e.g. 'what I do can determine whether my hayfever gets better or worse'; timeline-chronic assesses how long the patient thinks their illness will last (6 items, score 6-30) e.g. 'I expect to have hayfever for the rest of my life'; timeline -cyclical assesses perceptions about the pattern of their symptoms (4 items, score 4-20) e.g. 'my symptoms come and go in cycles'; and treatment control assesses the impact of treatment on control of the condition (5 items, score 5-25) e.g. 'my treatment can control my hayfever'. The emotional representation the patient holds towards their illness (6 items, score 6-30) e.g. 'I get depressed when I think about my hayfever' and illness coherence/understanding which assesses whether patients' comprehend their illness (5 items, score 5-25) e.g. 'I have a clear picture or understanding of my hayfever' are also assessed. These seven subscales are computed from responses to a series of statements to which the respondent indicates their agreement on a 5-point Likert scale, ranging from $1=$ strongly disagree to $5=$ strongly agree. Higher scores indicate stronger beliefs.

Beliefs about Medicines Questionnaire-Specific (BMQ-specific): Patients' views about the medication prescribed for their hayfever were assessed using the Specific version of the Beliefs about Medicines Questionnaire (BMQ), which has been validated for use in a range of clinical conditions and has been shown to have good internal consistency and test-retest reliability [31]. The BMQ-specific measure comprises two 5 -item scales assessing personal beliefs about the necessity of the specifically prescribed medication for controlling their illness and concerns about the potential adverse consequences of taking it. In the BMQ-HF devised for this study, the word 'medicines' was replaced with 'antihistamine tablets', 'nasal spray' and 'eye drops', to create three versions of the specific measure. Respondents indicate their degree of agreement with each of the 10 items on a 5-point Likert scale, (1=strongly disagree; $5=$ strongly agree). Items are summed to give a necessity and concerns 
scale scores (each ranging from 5-25). Higher scores indicate stronger beliefs in necessity and greater concerns about the particular medication.

\section{Statistical analysis}

Statistical analysis was conducted using SPSS v14 for Windows. Missing items from IPQ-R scales were addressed by mean imputation as advised by the scale developer: if more than half of the subscale items were completed, the missing items were assigned values equal to the average of the completed items.

Relationships between illness and medication belief subscales and demographic factors were explored using Spearman's rank correlation coefficients (Mann-Whitney U test for gender). Patient subgroups were identified by hierarchical agglomerative cluster analysis of IPQ-R subscale scores, using Ward's method [32], taking as the resemblance coefficient, the squared Euclidean distance between illness beliefs as measured by the seven cognitive and emotional subscales of the IPQ$\mathrm{R}$ [33]. As IPQ-R subscales contain differing numbers of items, values were standardised by transformation into $\mathrm{Z}$ scores. The agglomeration schedule was examined to determine the most appropriate number of clusters in the data. Independent sample $t$-tests (95\% confidence intervals and equal variance assumed), were conducted to determine whether there were any significant differences between clusters in medication beliefs, age, duration of illness and age of SAR onset. Cluster differences in gender and experience of symptoms was investigated using $\mathrm{Chi}^{2}$ tests.

\section{Results}

\section{Participants}

Of the 586 questionnaires sent, 316 were returned (54\% response rate). $61 \%$ of respondents were female $(61 \%)$; mean age 40 years (SD 12.47). $81 \%$ reported moderate or severe symptoms and $76 \%$ reported symptoms $\geq 4$ days/week for more than 4 weeks in the preceding hayfever season. $63 \%$ reported using oral antihistamines regularly, $37 \%$ used nasal sprays regularly and $22 \%$ used eye drops regularly (Table 1 ).

\section{Patient beliefs}

All illness and treatment belief subscales demonstrated acceptable internal consistency with Cronbach's Alpha ranging from 0.70-0.91 (Table 2).

The most common symptoms attributed to SAR were sore eyes $(91 \%)$, sore throat $(66 \%)$, wheeziness $(63 \%)$, fatigue $(55 \%)$, breathlessness (55\%), sleep difficulties (53\%) and headaches (49\%). Some participants blamed hay fever for symptoms not commonly associated with SAR, e.g. upset stomach, loss of strength, pain, and nausea.

As causes of SAR, patients mainly endorsed immune and risk factors beyond their control, such as pollen (93\%), pollution (73\%), inherited condition (43\%), altered immunity (32\%). Fewer respondents selected psychological attributions such as stress/worry (16\%), or emotional state (9\%) (Table 3) [30]

\section{Relationships between patient beliefs and demographic fac- tors}

Females were more likely than males to believe that their hayfever was permanent or would last a long time $(\mathrm{p}=0.025)$. With increasing age, perceptions of personal controllability of their illness increased $(\mathrm{r}=0.13 ; \mathrm{p}=0.025)$ as did beliefs about needing to take antihistamines $(\mathrm{r}=0.15 ; \mathrm{p}=0.015)$ and concerns about nasal sprays $(\mathrm{r}=0.19 ; \mathrm{p}=0.009)$.
Later onset of SAR correlated positively with stronger perceptions of controllability of illness by treatment $(\mathrm{r}=0.14 ; \mathrm{n}=297 ; \mathrm{p}=0.019)$, more concerns about antihistamines $(r=0.17 ; \mathrm{p}=0.01)$ and nasal sprays $(\mathrm{r}=0.15 ; \mathrm{p}=0.047)$, and weaker beliefs that hayfever would last a long time or be permanent $(\mathrm{r}=-0.15 ; \mathrm{p}=0.008)$.

People with earlier age of onset were more likely to report better understanding of their hayfever (illness coherence) than those whose symptoms started later $(\mathrm{r}=-0.28 ; \mathrm{n}=297 ; \mathrm{p} \leq 0.001)$. Longer illness duration was associated with stronger beliefs in personal control $(\mathrm{r}=0.25$; $\mathrm{p} \leq 0.001)$, weaker beliefs in treatment control $(\mathrm{r}=-0.12 ; \mathrm{p}=0.03)$, perceptions that the illness would continue $(r=0.15 ; \mathrm{p}=0.008)$ and a better understanding of the illness (illness coherence) $(r=0.30 ; p \leq 0.001)$. Although statistically significant, these relationships were all relatively modest.

\section{Relationships between illness and medication beliefs (Table 4)}

Moderate associations $(r \geq 0.4)$ were found between beliefs that SAR has more severe consequences for the individual and concerns about medication. Stronger beliefs in the necessity for antihistamines were related to stronger illness identity and to more negative perceptions of the consequences of SAR. Participants reporting a better understanding of their illness (high illness coherence scores) tended to have fewer concerns about medication (nasal spray, antihistamine tablets and eye drops) than those reporting poor understanding of their SAR (Table 4).

\begin{tabular}{|c|c|c|c|}
\hline Demographic variable & $\mathbf{N}$ & & (\%) \\
\hline $\begin{array}{l}\text { Male } \\
\text { Female }\end{array}$ & $\begin{array}{l}121 \\
194\end{array}$ & & $\begin{array}{l}(38) \\
(62)\end{array}$ \\
\hline $\begin{array}{l}\text { Current age (years) : } \\
\text { Mean (SD) }\end{array}$ & 40.3 & & $(12.47)$ \\
\hline Median & & 40 & \\
\hline Range & & $17-65$ & \\
\hline \multicolumn{4}{|l|}{ Experience of hay fever } \\
\hline $\begin{array}{l}\text { Age developed hay fever (years): } \\
\text { Mean (SD) }\end{array}$ & 19.39 & & $(12.62)$ \\
\hline Median & & 16 & \\
\hline $\begin{array}{l}\text { Duration of symptoms (years): } \\
\text { Mean (SD) } \\
\text { Median }\end{array}$ & 21 & 20 & $(12.70)$ \\
\hline Self-reported severity of symptoms: & $\mathbf{N}$ & & $(\%)$ \\
\hline $\begin{array}{l}\text { Mild } \\
\text { Moderate } \\
\text { Severe }\end{array}$ & $\begin{array}{l}63 \\
192 \\
50\end{array}$ & & $\begin{array}{l}(21) \\
(63) \\
(16)\end{array}$ \\
\hline $\begin{array}{l}\text { Experiencing symptoms } \geq 4 \text { days per } \\
\text { week for more than } 4 \text { weeks }\end{array}$ & 201 & & (76) \\
\hline \multicolumn{4}{|l|}{ Medication use } \\
\hline Oral antihistamines: Regular & 198 & & (65) \\
\hline Occasional & 78 & & (26) \\
\hline Never & 27 & & (9) \\
\hline Nasal spray: Regular & 116 & & (39) \\
\hline Occasional & 98 & & (33) \\
\hline Never & 84 & & (28) \\
\hline Eye drops: Regular & 71 & & $(24)$ \\
\hline Occasional & 97 & & (33) \\
\hline Never & 125 & & (43) \\
\hline No. of different medications used: 1 & 83 & & $(27)$ \\
\hline 2 & 115 & & (37) \\
\hline 3 & 115 & & (37) \\
\hline
\end{tabular}

†Data missing from all categories

Table 1: Characteristics of respondents†. 
Citation: Smith H, Llewellyn C, Woodcock A, White P, Frew A (2012) Understanding Patients' Experiences of Hayfever and its Treatment: A Survey of Illness and Medication Cognitions. J Aller Ther S5:008. doi:10.4172/2155-6121.S5-008

Page 4 of 7

\begin{tabular}{|c|c|c|c|c|}
\hline & Mean (SD) & Median & $\begin{array}{l}\text { Min-max } \\
\text { score }\end{array}$ & Cronbach's $\alpha$ \\
\hline \multicolumn{5}{|l|}{ IPQ-R: } \\
\hline IIIness identity $(n=237)$ & $\begin{array}{l}6.73 \\
(3.37)\end{array}$ & 6.00 & $1-14$ & N/A \\
\hline Timeline $(n=314)$ & $\begin{array}{l}21.36 \\
(4.16)\end{array}$ & 22.00 & $10-30$ & 0.80 \\
\hline Timeline cyclical $(n=315)$ & $\begin{array}{l}12.78 \\
(3.18)\end{array}$ & 13.00 & $4-20$ & 0.70 \\
\hline Consequences $(n=314)$ & $\begin{array}{l}15.77 \\
(4.42)\end{array}$ & 15.00 & 6-29 & 0.78 \\
\hline Personal control $(n=314)$ & $\begin{array}{l}18.88 \\
(2.95)\end{array}$ & 19.00 & $10-26$ & 0.74 \\
\hline Treatment control $(n=314)$ & $\begin{array}{c}14.64 \\
(1.92)\end{array}$ & 15.00 & $9-20$ & 0.77 \\
\hline IIIness coherence $(n=314)$ & $\begin{array}{l}17.85 \\
(4.50)\end{array}$ & 19.00 & $5-25$ & 0.91 \\
\hline $\begin{array}{l}\text { Emotional representations } \\
(\mathrm{n}=314)\end{array}$ & $\begin{array}{l}11.57 \\
(3.94)\end{array}$ & 11.00 & $5-25$ & 0.85 \\
\hline \multicolumn{5}{|c|}{ BMQ-Specific ( $\mathrm{n}$ reflects number reporting use of medication) } \\
\hline \multicolumn{5}{|c|}{\begin{tabular}{l|l|} 
Necessity & \\
\end{tabular}} \\
\hline $\begin{array}{l}\text { Oral antihistamines } \\
(\mathrm{n}=254)\end{array}$ & $\begin{array}{l}14.85 \\
(4.23)\end{array}$ & 15.00 & $5-25$ & 0.83 \\
\hline Nasal spray $(n=189)$ & $\begin{array}{l}14.30 \\
(4.25)\end{array}$ & 14.00 & $5-25$ & 0.86 \\
\hline Eye drops $(n=143)$ & $\begin{array}{l}13.17 \\
(3.83)\end{array}$ & 12.00 & $5-22$ & 0.82 \\
\hline \multicolumn{5}{|l|}{ Concerns } \\
\hline $\begin{array}{l}\text { Oral antihistamines } \\
(n=258)\end{array}$ & $\begin{array}{l}12.00 \\
(3.44)\end{array}$ & 12.00 & $5-21$ & 0.71 \\
\hline Nasal spray $(n=191)$ & $\begin{array}{l}12.25 \\
(3.39)\end{array}$ & 12.00 & $5-21$ & 0.76 \\
\hline Eye drops $(n=143)$ & $\begin{array}{l}10.76 \\
(3.36)\end{array}$ & 10.00 & $5-20$ & 0.84 \\
\hline
\end{tabular}

Table 2: Means (SD), medians, ranges and Cronbach's Alpha values for illness perceptions (IPQ-R) and medication beliefs (BMQ).

\begin{tabular}{|c|c|c|}
\hline Cause & $\mathbf{N}$ & $\begin{array}{l}\% \text { of sample endorsing item } \\
\text { (agreeing/ strongly agreeing) }\end{array}$ \\
\hline Pollen & 293 & 93 \\
\hline Pollution in the environment & 232 & 73 \\
\hline Hereditary - 'it runs in my family' & 136 & 43 \\
\hline Altered immunity & 102 & 32 \\
\hline Chance or bad luck & 60 & 19 \\
\hline Stress or worry ${ }^{\dagger}$ & 51 & 16 \\
\hline Diet or eating habits & 47 & 15 \\
\hline Smoking & 43 & 14 \\
\hline My own behaviour ${ }^{\dagger}$ & 43 & 14 \\
\hline $\begin{array}{l}\text { My emotional state e.g. feeling } \\
\text { down, lonely, anxious, empty }{ }^{\dagger}\end{array}$ & 30 & 9 \\
\hline A germ or virus & 29 & 9 \\
\hline Overwork & 22 & 7 \\
\hline Alcohol & 19 & 6 \\
\hline Ageing & 16 & 5 \\
\hline $\begin{array}{l}\text { My mental attitude e.g. thinking } \\
\text { about life negatively }{ }^{\dagger}\end{array}$ & 10 & 3 \\
\hline Poor medical care in my past & 9 & 3 \\
\hline $\begin{array}{l}\text { Family problems or worries } \\
\text { caused my illness }^{\dagger}\end{array}$ & 8 & 3 \\
\hline My personality ${ }^{\dagger}$ & 5 & 2 \\
\hline Accident or injury & 5 & 2 \\
\hline
\end{tabular}

†Emotional casual attributions [38]

$$
\text { Table 3: Causal attributions of hay fever. }
$$

Emotional representations were positively associated with all medication beliefs, indicating that those with stronger medication concerns

\begin{tabular}{|c|c|c|c|c|c|c|}
\hline \multirow{3}{*}{$\begin{array}{l}\text { Beliefs about } \\
\text { hay fever } \\
\text { (IPQ-R) }\end{array}$} & \multicolumn{6}{|c|}{ Beliefs about hay fever medication (BMQ) } \\
\hline & \multicolumn{2}{|c|}{ Oral antihistamines } & \multicolumn{2}{|c|}{ Nasal spray } & \multicolumn{2}{|l|}{ Eye drops } \\
\hline & Necessity & Concerns & Necessity & Concerns & Necessity & Concerns \\
\hline IIIness identity & $.255^{\star \star \star}$ & .135 & .124 & .143 & .114 & .041 \\
\hline $\begin{array}{l}\text { Timeline } \\
\text { (acute/chronic) }\end{array}$ & $.305^{\star \star \star}$ & $.154^{*}$ & .090 & $.146^{*}$ & .087 & .097 \\
\hline $\begin{array}{l}\text { Timeline } \\
\text { cyclical }\end{array}$ & -.083 & $.177^{* *}$ & -.013 & .580 & .036 & $.179^{*}$ \\
\hline Consequences & $.458^{* * *}$ & $.437^{* \star *}$ & .127 & $.274^{* * *}$ & $.297^{\star \star *}$ & $.430^{* * *}$ \\
\hline $\begin{array}{l}\text { Personal } \\
\text { control }\end{array}$ & .098 & -.099 & .074 & .012 & .143 & .111 \\
\hline $\begin{array}{l}\text { Treatment } \\
\text { control }\end{array}$ & .059 & .026 & .083 & -.085 & .005 & .002 \\
\hline $\begin{array}{l}\text { IIIness } \\
\text { coherence }\end{array}$ & $-.133^{*}$ & $-.424^{\star * *}$ & -.039 & $-.199^{*}$ & -.043 & $-.397^{* \star *}$ \\
\hline $\begin{array}{l}\text { Emotional rep- } \\
\text { resentations }\end{array}$ & $.301^{* * *}$ & $.435^{\star \star *}$ & $.160^{*}$ & $.313^{* * *}$ & $.206^{*}$ & $.390^{* * *}$ \\
\hline
\end{tabular}
resentations

'Spearman's correlation coefficients

${ }^{*} p \leq 0.05^{* *} p \leq 0.005^{* * *} p \leq 0.001$ all others non significant

Table 4: Correlation coefficients $†$ between patient beliefs about hay fever medicines and perceptions about their hay fever.

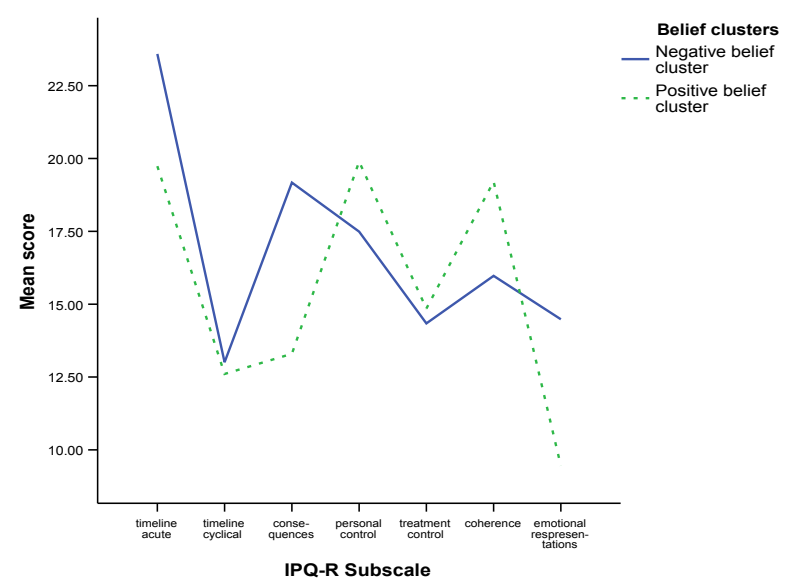

Figure 1: Clusters of negative and positive beliefs based on IPQ-R dimensions.

and beliefs in the need for medication were more likely to report being upset or depressed by SAR.

\section{Identification of two sub-groups of hayfever patients}

Cluster analysis of illness representations identified two subgroups of patients (Figure 1). Broadly speaking, 58\% had 'positive' beliefs and $42 \%$ had 'negative' beliefs. These two groups were similar in terms of age $(t=-0.61 ; d f=311 ; p>0.05)$, age of onset $(t=-0.03 ; d f=295 ; p>0.05)$, gender $(\chi 2=0.49 ; \mathrm{p}>0.05)$ and duration of illness $(\mathrm{t}=-0.72 ; \mathrm{df}=295$; $\mathrm{p}>0.05)$. However, those with negative beliefs were more likely to experience hayfever symptoms $\geq 4$ days/week during the season $\left(\chi^{2}=20.93\right.$; $\mathrm{p}<0.001)$ and to perceive their symptoms as more severe $\left(\chi^{2}=41.70\right.$; $\mathrm{p}<0.001)$.

Those with negative beliefs were more likely to perceive their illness as having greater emotional impact, greater consequences for their lives and as lasting longer. This group also reported a poorer understanding of their illness than those holding positive beliefs (Table 5). Consistently, those holding more negative beliefs attributed more symptoms to their hayfever, perceived they had less personal control over their 


\begin{tabular}{|c|c|c|c|c|}
\hline Variables & $\begin{array}{l}\text { Positive beliefs } \\
\text { cluster }\left(n=182^{\dagger}\right) \\
\text { mean }(S D)\end{array}$ & $\begin{array}{l}\text { Negative beliefs } \\
\text { cluster }\left(n=132^{\dagger}\right) \\
\text { mean }(S D)\end{array}$ & t & $\begin{array}{l}\text { Significance } \\
\text { (p) }\end{array}$ \\
\hline \multicolumn{5}{|l|}{$I P Q-R^{+}$} \\
\hline Illness identity & $\begin{array}{l}6.14(3.37) \\
(n=135)\end{array}$ & $\begin{array}{l}7.56(3.20) \\
(n=101)\end{array}$ & 3.27 & 0.001 \\
\hline Timeline $^{\ddagger}$ & $19.74(4.00)$ & $23.59(3.31)$ & 9.35 & $<0.001$ \\
\hline Personal control & $19.89(2.70)$ & $17.49(2.71)$ & -7.78 & $<0.001$ \\
\hline Treatment control & $14.85(1.83)$ & 14.34 (1.99) & -2.34 & 0.02 \\
\hline Illness coherence & $19.21(4.11)$ & $15.97(4.35)$ & -6.72 & $<0.001$ \\
\hline $\begin{array}{l}\text { Emotional represen- } \\
\text { tations } \mathbf{s}^{\ddagger}\end{array}$ & $9.45(2.58)$ & $14.48(3.61)$ & 13.68 & $<0.001$ \\
\hline Consequences & $13.30(3.04)$ & $19.17(3.70)$ & 15.43 & $<0.001$ \\
\hline Timeline -cyclical & $12.60(2.99)$ & $13.01(3.43)$ & 1.11 & 0.27 \\
\hline \multicolumn{5}{|l|}{ BMQ-Specific ${ }^{\dagger}$} \\
\hline \multicolumn{5}{|l|}{ Necessity } \\
\hline Antihistamines & $\begin{array}{l}14.06(4.11) \\
(n=151)\end{array}$ & $\begin{array}{l}16.02(4.16) \\
(n=103)\end{array}$ & 3.72 & $<0.001$ \\
\hline Nasal spray $\ddagger$ & $\begin{array}{l}13.92(3.90) \\
(n=98)\end{array}$ & $\begin{array}{l}14.70(4.59) \\
(n=91)\end{array}$ & 1.26 & 0.21 \\
\hline Eye drops & $\begin{array}{l}12.73(4.06) \\
(n=78)\end{array}$ & $\begin{array}{l}13.71(3.49) \\
(n=65)\end{array}$ & 1.53 & 0.13 \\
\hline \multicolumn{5}{|l|}{ Concerns } \\
\hline Antihistamines & $\begin{array}{l}10.88(3.03) \\
(n=154)\end{array}$ & $\begin{array}{l}13.66(3.35) \\
(n=104)\end{array}$ & 6.92 & $<0.001$ \\
\hline Nasal spray & $\begin{array}{l}11.37(3.16) \\
(n=102)\end{array}$ & $\begin{array}{l}13.26(3.39) \\
(n=89)\end{array}$ & 3.98 & $<0.001$ \\
\hline Eye drops & $\begin{array}{l}9.84(3.21) \\
(n=82)\end{array}$ & $\begin{array}{l}11.98(3.19) \\
(n=61)\end{array}$ & 3.96 & $<0.001$ \\
\hline
\end{tabular}

tn as described unless otherwise indicated in the table

‡equal variances not assumed

Table 5: Independent samples t-test results across self-report measures for cluster groups.

illness and were less likely to believe that treatment could control their hayfever (Table 5).

Patients with more negative beliefs about their SAR had stronger belief in the necessity of taking antihistamine tablets to improve their health, but there was no difference for nasal sprays or eye drops (Table 5). However, patients with more negative beliefs reported greater concerns about all three types of medication (Table 5).

\section{Discussion}

This is the first study to use the SRM framework to explore the beliefs of patients with hayfever about their illness and its treatment $[18,19]$. The analysis revealed clear patterns of beliefs, linked to symptom reporting and have implications for patient care.

The strongest correlations were found between illness cognitions and medication beliefs. Patients reporting good understanding of their illness were less likely to have concerns regarding medication. Those who reported strong concerns about their medication and also held strong beliefs that medication was necessary for their health were more likely to experience emotional consequences, such as being upset or depressed because of SAR.

These findings have important implications for patient management. As most SAR is managed in the community, appropriate selfmanagement is vital to optimising symptom control, and reducing disease impact. Patients' understanding of their SAR could be improved by educational strategies, including wider use by community physicians and pharmacists of existing leaflets informing patients about the causes,

symptoms and likely impact of SAR and the range of available medications. Those who had experienced SAR for longer reported stronger personal control beliefs and better understanding of SAR. This may reflect an adaptive approach to self-management as patients get used to having SAR. If during the consultation, the clinician identifies someone with negative beliefs they should encourage the patient to consider alternative perspectives that may encourage adaptive problem focused coping strategies. Even those with more positive illness cognitions did not strongly believe that their treatment would be effective. There are several possible explanations beyond the simple conclusion that treatment is not very effective. Incomplete medication adherence could lead to poor symptom control, if patients believe that medication will not help their particular symptoms. Strong personal control beliefs associated with low beliefs in the necessity of medicines and high medication concerns may mean that patients use behavioural management options rather than drug therapy. These beliefs could be explored by the clinician and alternative pharmaceutical options discussed.

In general, patients did not strongly believe that their medication was necessary to their health. Patients' beliefs about medication are not necessarily rational from a medical perspective [20], and they may be reluctant to disclose these beliefs to health professionals. Discussion of information provided in leaflets could help elicit the patient's own beliefs, concerns and expectations [34]. Having explored these and having considered them in relation to treatment alternatives, the practitioner and patient could agree an appropriate treatment plan. Through shared ownership of the decision the patient is more likely to take the medication as recommended.

For example White et al. found that $64 \%$ of hayfever patients who were prescribed regular nasal steroids and antihistamines, did not take their medication as recommended [2]. The SRM asserts that beliefs affect the coping strategies that people choose [18,19], and this has been shown to affect adherence to medication [16]. In the SRM, nonadherence results from incongruence within the person's illness model. Previous studies have demonstrated that stronger concerns about the potential adverse effects of medication $[16,25]$ and more negative timeline and cure/control beliefs [26] are related to reduced adherence levels in asthma. Interventions could be designed to address concerns about medications and to strengthen beliefs about personal control alongside treatment control.

Many patients considered their SAR was caused by pollen or pollution in the environment, or a hereditary condition. This is similar to causal beliefs reported by members of an allergy network [29]. However, a minority attributed their illness to psychological factors such as stress, worry, or their emotional state. Beliefs about cause also influence health behaviours such as following management advice and have been targets for intervention. Interventions aimed at changing the causal beliefs of patients (e.g. patients whose perceptions of the cause of their myocardial infarction were unrelated to epidemiological evidence) have successfully changed patient outcomes [27]. Little work has been conducted in other, less serious conditions.

Examining patterns of beliefs may be better for identifying 'at risk' groups for intervention than targeting individual beliefs [33]. Cluster analyses have been applied to many patient groups, including those with chronic pain [35] and hypertension [36]. In the present study, cluster analysis revealed that people with more negative belief patterns were more likely to perceive that their SAR would be permanent, and perceived more severe consequences. This subgroup had less understanding of SAR and reported stronger emotional representations, as compared to patients with more positive beliefs. Patients with more 
negative beliefs about SAR were also more likely to believe in taking antihistamines. The lack of relationships between beliefs and use of nasal sprays or eye drops may reflect the smaller numbers using these, or perhaps the more targeted nature of symptom relief as compared to antihistamine tablets. Negative illness perceptions have been linked to higher levels of psychological distress and less adaptive coping strategies in allergy sufferers [29]: perhaps those reporting more negative beliefs may be at increased risk of these outcomes. Future studies could clarify how patterns of beliefs link to anxiety and depression, coping style and adherence. Interventions could focus on promoting more positive beliefs and teaching new coping strategies (pharmacotherapy and behavioural approaches).

The present study has some limitations. The cross-sectional design means we cannot determine whether medication beliefs cause beliefs about the illness or vice versa. Similarly, as SAR symptoms vary according to time of year, beliefs captured at one time point may not remain stable all year round. A repeated measures design would better capture the cyclical nature of SAR and indicate the optimum timing for intervention. The sample only included patients who have consulted a general practitioner and ignores those who only self-medicate with over the counter remedies. It remains unknown whether beliefs or symptom severity differ between these two groups.

Despite these limitations, the study findings are relevant to clinical practice. If clinicians gain a better understanding of their patients' views about their illness and treatment, this creates a firmer foundation for clinician-patient partnership [37]. Our findings demonstrate that the SRM illness perceptions approach offers a useful framework for eliciting patients' underlying cognitive models of SAR and may help facilitate discussion about self management strategies with those holding negative beliefs, with the aim of arriving at appropriate and mutually agreed treatment plans.

\section{Acknowledgements}

The authors wish to thank the staff and patients at the four participating general practices for their support. Additional thanks to Raj Meeta for advice on the study design, Louise Brown for co-ordinating the study, Joan Dunleavey and Martine Cross for data entry, and Kate Perry and Matthew Hankins for data cleaning and preliminary analysis.

\section{Contributions}

HS and PW designed the study. All authors (HS, CL, AW, PW \& AF) contributed to the interpretation of the data and preparation and revision of the manuscript.

\section{Source of Funding}

Unrestricted educational grant from Schering Plough.

\section{References}

1. Jarvis D, Burney $P$ (1998) ABC of allergies. The epidemiology of allergic disease. BMJ 316: 607-610.

2. White P, Smith H, Baker N, Davis W, Frew A (1998) Symptom control in patients with hay fever in UK general practice: how well are we doing and is there need for immunotherapy? Clin Exp Allergy 28: 266-270

3. Sibbald B, Rink E (1991) Epidemiology of seasonal and perennial rhinitis: clinical presentation and medical history. Thorax 46: 895-901.

4. Butland B, Strachan DP, Lewis S, Bynner J, Butler N, et al. (1997) Investigation into the increase in hay fever and eczema at age 16 observed between 1558 and 1970 British Birth cohorts. BMJ 315: 717-721.

5. Devenny A, Wassall H, Ninan T, Omran M, Khan SD, et al. (2004) Respiratory symptoms and atopy in children in Aberdeen: questionnaire studies of a defined school population repeated over 35 years. BMJ 329: 489-490.

6. Gupta R, Sheikh A, Strachan DP, Anderson HR (2007) Time trends in allergic disorders in the UK. Thorax 62: 91-96.
7. Fleming DM, Crombie DL (1987) Prevalence of asthma and hay fever in Eng land and Wales. BMJ 294: 279-283.

8. Van Hoecke H, Vastesaeger N, Dewulf L, Sys L, van Cauwenberge P (2006) Classification and management of allergic rhinitis patients in general practice during pollen season. Allergy 61: 705-711.

9. Bachert C (2002) Quality of life: Improvement due to treatment. Clinical \& Experimental Allergy Reviews 2: 73-78.

10. Juniper EF (1998) Rhinitis management: the patient's perspective. Clin Exp Allergy 28: 34-38.

11. Laforest L, Bousquet J, Pietri G, Sazonov Kocevar V, Yin D, et al. (2005) Quality of life during pollen season in patients with seasonal allergic rhinitis with or without asthma. Int Arch Allergy Immunol 136: 281-286.

12. Majani G, Baiardini I, Giardini A, Senna GE, Minale P, et al. (2001) Healthrelated quality of life assessment in young adults with seasonal allergic rhinitis. Allergy 56: 313-317.

13. Meltzer EO, Nathan RA, Selner JC, Storms W (1997) Quality of life and rhinitic symptoms: Results of a nationwide survey with the SF-36 and RQLQ questionnaires. J Allergy Clin Immunol 99: S815-819.

14. Stuck BA, Czajkowski J, Hagner AE, Klimek L, Verse T, et al. (2004) Changes in daytime sleepiness, quality of life, and objective sleep patterns in seasonal allergic rhinitis: A controlled clinical trial. J Allergy Clin Immunol 113: 663-668.

15. Scadding GK, Richards DH, Price MJ (2000) Patient and physician perspectives on the impact and management of perennial and seasonal allergic rhinitis. Clin Otolaryngol Aliied Sci 25: 551-557.

16. Horne R, Weinman J (1999) Patients' beliefs about prescribed medicines and their role in adherence to treatment in chronic physical illness. J Psychosom Res 47: 555-567.

17. Llewellyn CD, Miners AH, Lee CA, Harrington C, Weinman J (2003) The illness perceptions and treatment beliefs of individuals with severe haemophilia and their role in adherence to home treatment. Psychol Health 18: 185-200.

18. Leventhal H, Meyer D, Nerenz D (1980) The common sense representation of illness danger. In: Rachman S (ed) Contributions to medical psychology. Pergamon Press, New York, pp: 7-30

19. Leventhal H, Benyamini Y, Brownlee S, Diefenbach M, Leventhal EA, et al. (1997) Illness representations: theoretical foundations. In: Petrie KJ, Weinman $\mathrm{J}$ (eds) Perceptions of health and illness. Harwood Academic Press, Amsterdam, pp: 19-46.

20. Britten N (1994) Patients' ideas about medicines: a qualitative study in a general practice population. B J Gen Prac 44: 465-468.

21. Horne R (1997) Representations of medication and treatment: advances in theory and measurement. In: Petrie KJ, Weinman J (Eds) Perceptions of health and illness: current research and applications. Harwood Academic Press, Amsterdam, pp: 155-187.

22. Hagger MS, Orbell S (2003) A meta-analytic review of the common-sense model of illness representations. Psychol Health 18:141-184.

23. Llewellyn CD, McGurk M, Weinman J (2007) Illness and treatment perceptions after diagnosis with head and neck cancer. Is Leventhal's Common Sense Model a useful framework for determining changes in outcomes over time? J Psychosom Res 63: 17-26.

24. Scharloo M, Kaptein AA, Weinman J, Hazes JM, Willems LN, et al. (1998) IIIness perceptions, coping and functioning in patients with rheumatoid arthritis, chronic obstructive pulmonary disease and psoriasis. J Psychosom Res 44 573-585.

25. Horne R, Weinman J (2002) Self-regulation and self-management in asthma: exploring the role of illness perceptions and treatment beliefs in explaining nonadherence to preventer medication. Psychol Health 17: 17-32.

26. Jessop DC, Rutter DR (2003) Adherence to asthma medication: The role of illness representations. Psychol Health 18: 595-612.

27. Petrie KJ, Cameron LD, Ellis CJ, Buick D, Weinman J (2002) Changing illness perceptions after myocardial infarction: An early intervention randomized controlled trial. Psychosom Med 64: 580-586. 
Citation: Smith H, Llewellyn C, Woodcock A, White P, Frew A (2012) Understanding Patients' Experiences of Hayfever and its Treatment: A Survey of Illness and Medication Cognitions. J Aller Ther S5:008. doi:10.4172/2155-6121.S5-008

28. O'Rourke A, Hampson SE (1999) Psychosocial outcomes after an MI: An evaluation of two approaches to rehabilitation. Psychol Health Med 4: 393-402.

29. Knibb RC, Horton SL (2008) Can illness perceptions and coping predict psychological distress amongst allergy sufferers? Br J Health Psychol 13: 103-119.

30. Moss-Morris R, Weinman J, Petrie K, Horne R, Cameron L, et al. (2002) The Revised IIIness Perception Questionnaire (IPQ-R). Psychol Health 17: 1-16.

31. Horne R, Weinman J, Hankins M (1999) The Beliefs about Medicines Questionnaire: The development and evaluation of a new method for assessing the cognitive representation of medication. Psychol Health 14: 1-24.

32. Ward JH (1963) Hierarchical grouping to optimize an objective function. J Am Stat Assoc 58: 236-244.

33. Clatworthy J, Buick D, Hankins M, Weinman J, Horne R (2005) The use and reporting of cluster analysis in health psychology: A review. $\mathrm{Br} \mathrm{J}$ Health Psychol 10: $329-358$

34. White P, Smith H, Webley F, Frew A (2004) A survey of the quality of information leaflets on hay fever available from general practices and community pharmacies. Clin Exp Allergy 34: 1438-1443.

35. Hobro N, Weinman J, Hankins M (2004) Using the self-regulatory model to cluster chronic pain patients: the first step towards identifying relevant treatments. Pain 108: 276-283.

36. Weir MR, Maibach EW, Bakris GL, Black HR, Chawla P, et al. (2000) Implications of a health lifestyle and medication analysis for improving hypertension control. Arch Inter Med 160: 481-90.

37. Royal Pharmaceutical Society of Great Britain (1997) From compliance to concordance. Achieving shared goals in medicine taking. London Pharmaceutical Press. 